\title{
USE OF HOST AGGREGATIONS AS MATING SITES BY CHRYSAGRIA ALTICOPHAGA (DIPTERA: SARCOPHAGIDAE)*
}

\author{
By William G. EBERHARD
}

Smithsonian Tropical Research Institute and Escuela de Biologia, Universidad de Costa Rica, Ciudad Universitaria, Costa Rica

Females of the newly described species Chrysagria alticophaga Lopes and Achoy oviposit on larvae of the chrysomelid beetle Altica sp. (Lopes and Achoy 1986). Each parasitized beetle larva produces a single fly larva. Adult beetles often form loose aggregations of up to several hundred individuals on their host plants. This note reports observations of adult $C$. alticophaga flies at two such adult aggregations in Costa Rica. Male flies apparently use beetle aggregations as sites to encounter females.

Observations were made on 24-25 Jan. 1987 on Cufea sp. (Litraceae) plants at the Wilson Botanical Garden near San Vito de Java, Puntarenas Province, and 23-25 Nov. 1988 on a single Ludwigia octovalvis (Onagraceae) plant in San Rafael de Escazu, San José Province. Flies were identified by comparing their genitalia with the figures in Lopes and Achoy 1986. The beetles (all of the same species) cannot at present be determined to species (S. Shute and R. White, pers. comm.); voucher specimens are deposited in the U.S. National Museum, the British Museum (Natural History), and the Museo Nacional of Costa Rica.

During the day the beetles in both aggregations were relatively dispersed on one or a few plants, with the estimated 100-300 beetles in each aggregation spread over 1-2 square meters. In both aggregations $C$. alticophaga flies were found perched among the beetles on the plants when the aggregations were checked during the day. The San Vito aggregation was also checked on two nights; the beetles were more tightly clumped and there were 4-6 flies perched among them.

Observations of individual flies late in the morning at both sites showed that they spent most of the time motionless or grooming, perched near the tips of small branches or at the tops of plants. They

*Manuscript received by the editor March 24, 1989. 
showed no tendency to perch on leaves with beetle feces on them, nor to feed on feces when they were present, though on several occasions flies in San Rafael repeatedly extended their probosces as they walked over or under a leaf (I never saw a fly extend its proboscis in San Vito). Flies changed perches on the order of once every 1-10 minutes, sometimes after flying toward a passing insect or sometimes apparently spontaneously. On four occasions (two in San Vito, two in San Rafael) flies flew at each other and engaged in brief tussles, but in general the flies did not interact with each other.

Collections of flies made late in the morning at both aggregations (flies were captured one by one with a small plastic bag to avoid disturbing the aggregated beetles) showed a strong bias to males: in San Vito 21 solitary males, 4 solitary females, and one mating pair were captured; in San Rafael 15 solitary males, 1 solitary female, and 1 mating pair were caught. Additional samples taken with a sweep net at San Vito in a similar stand of Cufea sp. 10-30 m away but where the beetles were not present confirmed that the flies were concentrated around the beetles: while 26 of 33 muscoid flies captured within the beetle aggregation were $C$. alticophaga, none of 22 captured by sweeping away from the aggregation were this species. A further collection of 6 solitary flies at night in this aggregation of beetles were all $C$. alticophaga -3 males and 3 females.

\section{Discussion}

Chrysagria alticophaga were strongly aggregated near groups of the adults of their host. Several lines of evidence suggest that the flies were aggregated in order to mate. Two mating pairs were found, and several tussles, which may have been mating attempts, were seen. Male flies were much more common than females, as is usually the case in mating aggregations of insects (Thornhill and Alcock 1983). In contrast, the sex ratio of flies raised from beetle larvae did not differ significantly from unity (84 males and 68 females).

It is unlikely that the flies visited the beetle aggregations either to feed or to ovipost. Flies often did not feed. They seldom extended their mouthparts, and when they did so they touched only the surfaces of leaves; they showed no interest in sites where beetles had fed or defecated. Since the flies parasitize larvae rather than adult beetles, and the plants on which the beetles were gathered had few or no 
larve (those in San Vito had no larvae whatsoever; the beetles were apparently in reproductive diapause, as none of 25 females dissected had any eggs even one fourth the length of mature eggs). Thus the sites of $C$. alticophaga seem to resemble most the landmark mating sites used by some other insects (Thornhill and Alcock 1983). Perhaps the use of these sites by the flies is related somehow to cues used by females when they search for host larvae.

The large numbers of $C$. alticophaga I collected from each beetle aggregation were surprising since during any one inspection I usually saw only 3-5 flies. This suggests that either I was unable to spot many of the individuals, or that individual flies stay only a short time near the beetles.

\section{ACKNOWLEDGMENTS}

I thank L. D. Gomez and P. Raven for plant identifications, R. White and S. Shute for beetle identifications, R. Achoy for the loan of his fly collection, and the Vicerrectoria de Investigación of the Universidad de Costa Rica for financial support.

\section{REFERENCES}

Lopes, H. de S. AND R. M. AChOy. 1986. On Chrysagria (Diptera, Sarcophagidae) with descriptions of two new species, one of them living on the larvae of Altica sp. (Coleoptera, Chrysomelidae). Rev. Bras. Biol. 46:272-276.

Thornhill, R. AND J. Alcock, 1983. The evolution of insect mating systems. Harvard Univ. Press, Cambridge, MA. 1-547. 

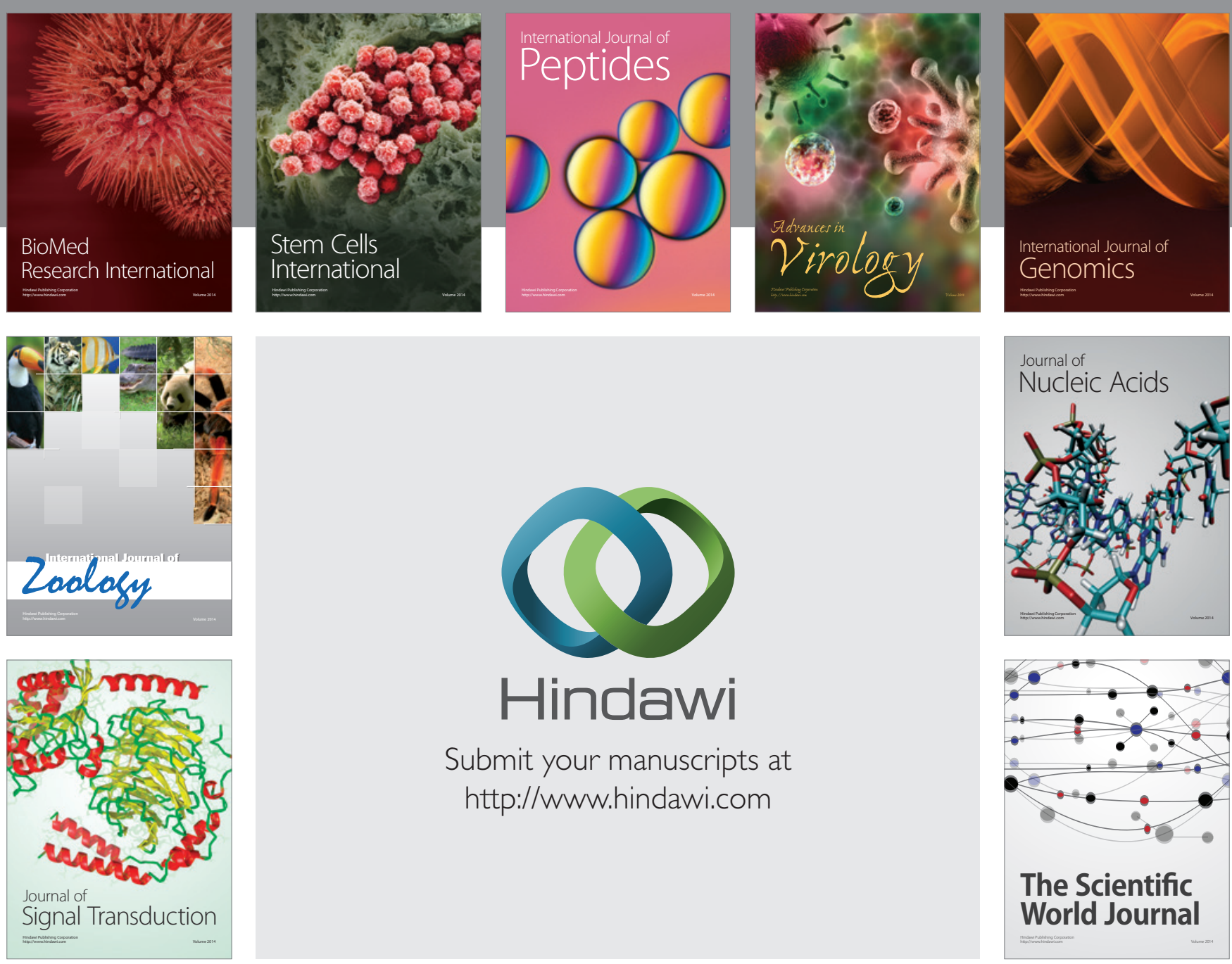

Submit your manuscripts at

http://www.hindawi.com
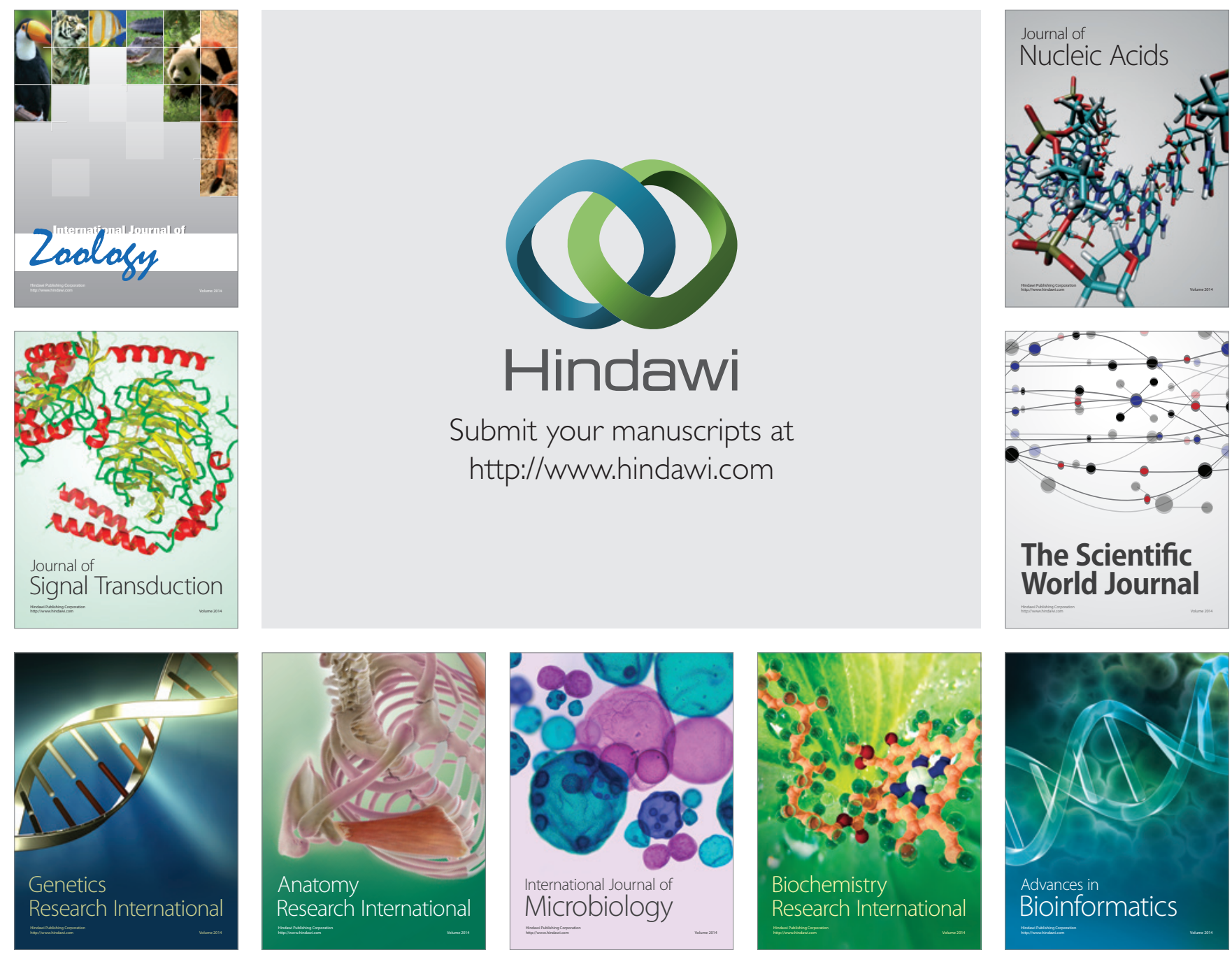

The Scientific World Journal
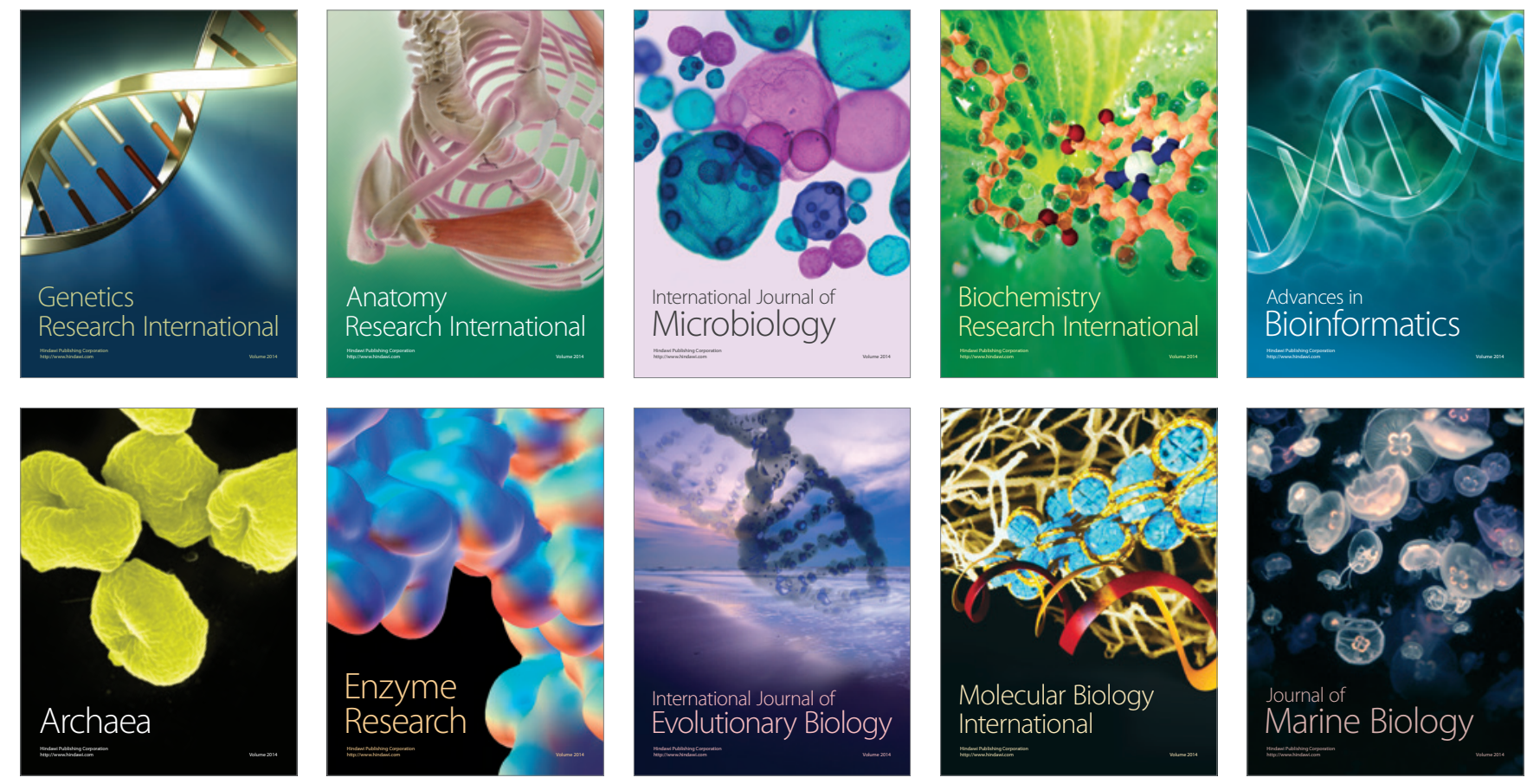